\title{
Role of Brush Biopsy and DNA Cytometry for Prevention, Diagnosis, Therapy, and Followup Care of Oral Cancer
}

\author{
Alfred Böcking, ${ }^{1}$ Christoph Sproll, ${ }^{2}$ Nikolas Stöcklein, ${ }^{3}$ Christian Naujoks, ${ }^{2}$ \\ Rita Depprich, ${ }^{2}$ Norbert R. Kübler, ${ }^{2}$ and Jörg Handschel ${ }^{2}$ \\ ${ }^{1}$ Institute of Cytopathology, Heinrich-Heine-University, Moorenstraße 5, 40225 Düsseldorf, Germany \\ ${ }^{2}$ Department for Cranio- and Maxillofacial Surgery, Heinrich-Heine-University, Moorenstraße 5, 40225 Düsseldorf, Germany \\ ${ }^{3}$ Department of General, Visceral, and Pediatric Surgery, University Hospital Düsseldorf, Heinrich-Heine-University, \\ 40225 Düsseldorf, Germany \\ Correspondence should be addressed to Alfred Böcking, alfred.boecking@uni-duesseldorf.de
}

Received 30 September 2010; Accepted 21 November 2010

Academic Editor: Pankaj Chaturvedi

Copyright (c) 2011 Alfred Böcking et al. This is an open access article distributed under the Creative Commons Attribution License, which permits unrestricted use, distribution, and reproduction in any medium, provided the original work is properly cited.

\begin{abstract}
Late diagnosis resulting in late treatment and locoregional failure after surgery are the main causes of death in patients with oral squamous cell carcinomas (SCCs). Actually, exfoliative cytology is increasingly used for early detection of oral cancer and has been the subject of intense research over the last five years. Significant advances have been made both in relation to screening and evaluation of precursor lesions. As this noninvasive procedure is well tolerated by patients, more lesions may be screened and thus more oral cancers may be found in early, curable stages. Moreover, the additional use of DNA image cytometry is a reasonable tool for the assessment of the resection margins of SCC. DNA image cytometry could help to find the appropriate treatment option for the patients. Finally, diagnostic DNA image cytometry is an accurate method and has internationally been standardized. In conclusion, DNA image cytometry has increasing impact on the prevention, diagnostic, and therapeutical considerations in head and neck SCC.
\end{abstract}

\section{Introduction}

Patients with squamous cell carcinomas of the oral cavity have a fair prognosis with an overall 5-year survival rate of about $45 \%$ [1]. Unfortunately, this figure has not substantially improved during the past 30 years [2]. Late diagnosis resulting in late treatment and locoregional failure after surgery or even after combined surgery and radiotherapy are the main causes of death in patients with oral squamous cell carcinomas.

These days, an alternative method for the examination of oral lesions is exfoliative cytology. It is based on the technique of Papanicolaou, which is accepted worldwide, as a successful method in order to screen for epithelial dysplasias in situ or invasive carcinomas of the uteri cervix. Currently, exfoliative cytology is increasingly used for early detection of oral cancer and has been the subject of intense research over the last five years $[3,4]$. Significant advances have been made both in relation to screening and in the evaluation of precursor lesions [5-11]. Although mucosal biopsy is still regarded as the gold standard for definitive oral cancer diagnosis, exfoliative cytology is a valuable tool for the noninvasive evaluation of a range of potentially preneoplastic oral mucosa lesions, like leuko-/erythroplakias and lichen ruber. The cytometric detection of DNA aneuploidy in exfoliated suspicious respectively dysplastic cells, qualifies these as malignant, up to two years earlier than cytology or histology alone $[12,13]$.

\section{Prevention}

2.1. Precursor Lesions of Oral Cancer. Oral carcinogenesis proceeds through a stepwise accumulation of (cyto)genetic changes over time. Because the oral cavity is easy to examine and risk factors for oral cancer are known, there is great opportunity to improve patient outcomes through diagnosis and treatment of premalignant lesions before the 
development of invasive oral carcinoma [14]. In contrast to the oral premalignant conditions, oral premalignant lesions are morphologically abnormal solitary or multiple areas of mucosa that are typically white, red, speckled or verrucous in appearance. The WHO classification [15] combines leukoplakia and erythroplakia into "precursor lesions," with a $6.8 \%$ estimated rate of transformation of oral leukoplakias to cancer. It identifies proliferative verrucous leukoplakia as a separate high risk lesion with minimal cytological atypia. Oral lichen planus, a chronic inflammatory condition, also is associated with an increased risk of cancer development of about 3\% [16, 17].

2.2. Indications for Brush Biopsy. Screening for oral cancer and its precursor lesions may be performed by dentists, dental surgeons, and other health care professionals. Exfoliative cytology, taking brush biopsies, is advocated for evaluation of macroscopically suspicious lesions of the oral mucosa that are detected clinically by screening. This may be followed by a mucosal scalpel biopsy. Yet, exfoliative cytology may replace tissue biopsy in lesions that are clinically not obviously suspicious for malignancy but nevertheless need surveillance. As tissue biopsy is associated with lower compliance by patients as compared to brush biopsy, this noninvasive approach may lead to a higher number of investigated suspicious oral lesions and thus to an increased rate of curable cancers, identified in early stages.

\section{Sampling of Cells}

Collection devices suitable to obtain cells from the superficial and intermediate layers of the oral mucosa may be conventional brushes, as used for endocervical sampling by gynecologists, such as the CytoBrush and Orca Brush (Figure 1). The brush is rotated under slight pressure several times on the suspicious lesion. Cells are then immediately smeared on glass slides and fixed with alcoholic spray. Signs of dysplasia and malignancy will also be detected cytologically in the upper layers of the squamous epithelium due to the principle of migration of cells from basal to superficial layers. The degree of nuclear abnormality in the surface layers reflects the degree of disturbance of maturation of the whole thickness of the epithelium. Thus, transepithelial sampling is not required to diagnose dysplasia and malignancy of the squamous epithelium on brush biopsies.

\section{Assessment of Dysplasia}

There are several schemes for grading dysplasia in biopsies of oral precursor lesions. The WHO classification provides a five-step system: hyperplasia, mild, moderate, and severe dysplasia followed by carcinoma in situ [15]. Squamous cell carcinoma will develop from antecedent dysplastic oral mucosal lesions if an early diagnosis has not been made and treatment given. Early diagnosis within stages Tis or T1 correspond to a vastly improved 5-year survival rate when compared with more advanced lesions $(96,7 \%)[17,18]$. It is the task of a cytopathologist to identify nuclear abnormalities

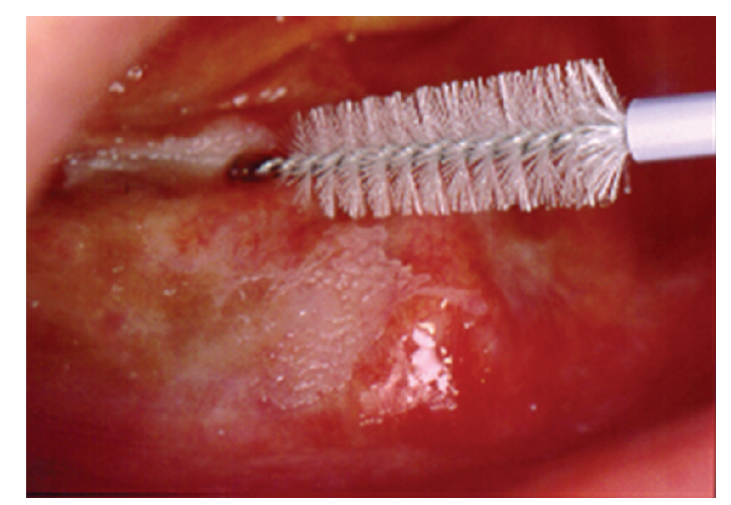

FIGURE 1: Brush biopsy from an oral verrucous leukoplakia.

in squamous cells collected to predict the histological grade of dysplasia. The diagnostic criteria used are well known and similar to those in cervical exfoliative cytology according to Papanicolaou [4]. Although the degree of dysplasia can be predicted on cytological samples (Figure 2), tissue biopsy is usually performed when dysplasia is detected cytologically, to confirm its grade and exclude the presence of invasion. The latter cannot be reliably assessed by exfoliative cytology alone. However, poor interobserver reproducibility in the histological assessment of oral premalignant lesions is well described [8].

\section{Diagnostic Impact}

5.1. Spectrum of Cytological Diagnoses. Apart from squamous cell carcinoma and its precursors (dysplasias), further neoplasias can be specifically diagnosed cytologically (e.g., naevuscell naevi, malignant melanomas, basalcell carcinomas, and malignant lymphomas). Moreover, a spectrum of non-neoplastic diseases can be differentiated using exfoliative cytology, for example, pemphigus vulgaris, Candida, herpes simplex, and HPV infections [4].

5.2. Diagnostic Accuracy of Cytology. Cytopathologic evaluation of oral brush biopsies from leukoplakias and erythroplakias as a single method yields sensitivities for the detection of oral cancer slightly below those of histopathologic evaluation of scalpel biopsies, reported to be 97,5\% [19]. Remmerbach et al. [5, 20] documented 91,3\% and 94,6\% sensitivity of oral brush biopsy and Maraki et al. [12] even $100 \%$ for the detection of oral cancer, including the in situ stage. Respective specificities were $99,5 \%, 95,1 \%$, and $97,4 \%$. Moreover, $24,1 \%$ of cancers were identified in early, curable stages Tis and T1 [20].

It is supported by an increasing number of data that oral cytology is also a valuable technique for the assessment of oral premalignant lesions $[3,12,21]$. Exfoliative cytology has been shown to detect dysplasia in suspicious oral lesions with high sensitivity and specificity by several groups [20].

Up to $5-14 \%$ of oral brush biopsies may yield to equivocal cytological diagnoses $[5,20]$. Underlying diagnoses are mild, moderate, or marked dysplasia, abnormal regenerating 


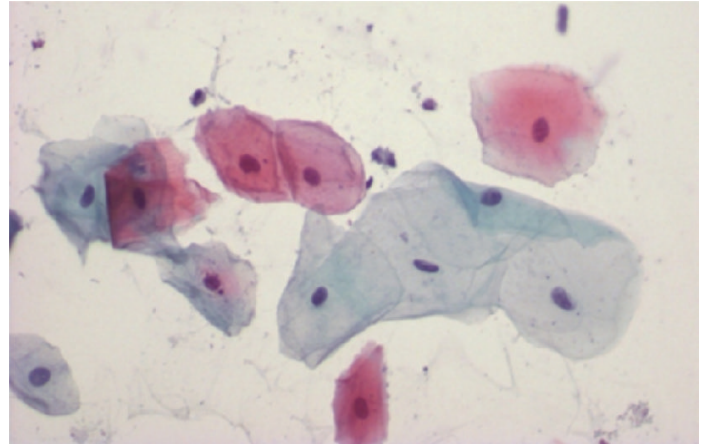

(a)

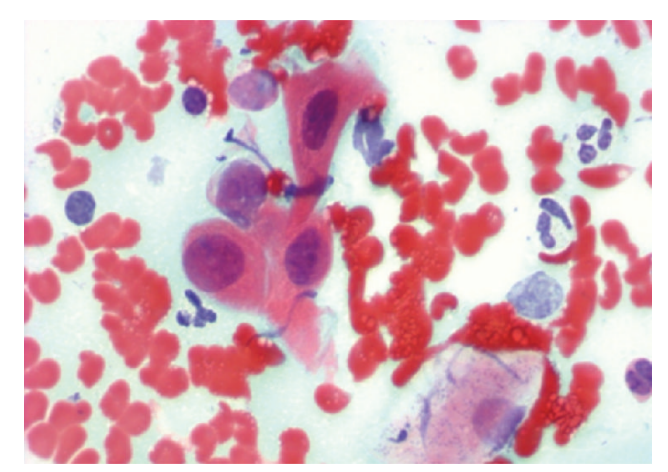

(b)

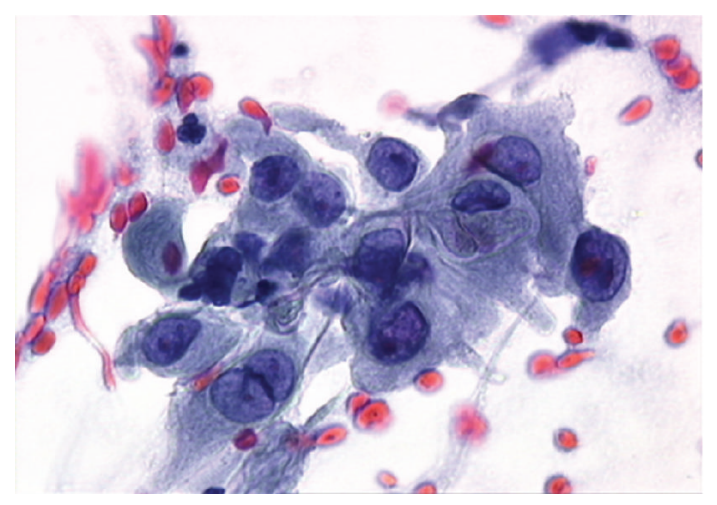

(c)

Figure 2: Normal (a), dysplastic (b), and malignant (c) oral squamous cells from brush biopsy, Papanicolaou stained, 630x.

squamous epithelium, or just scarcity of abnormal cells. In these cases, ancillary methods are desirable that, nevertheless, allow more definite, correct cytological diagnoses.

Meanwhile, use of auxiliary methods such as DNA image cytometry, AgNOR analysis, and multimodal cell analysis has been shown to significantly increase diagnostic accuracy of oral cytology $[12,13,20,22,23]$. These methods are only applied on those samples that reveal doubtful or suspicious (dysplastic) cells, on neither cytologically normal nor frankly malignant ones.

\section{Auxiliary Cytometry}

DNA image cytometry is based on microdensitometric DNA measurements of several hundred atypical cells in routine

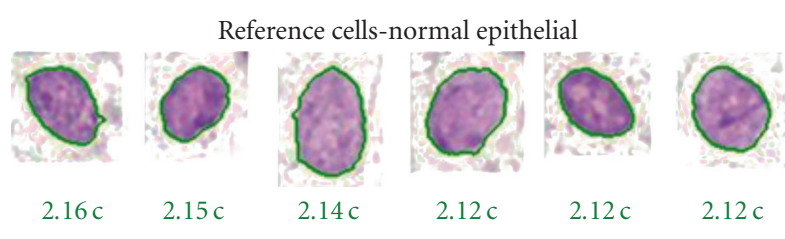

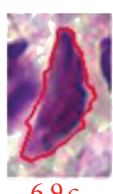
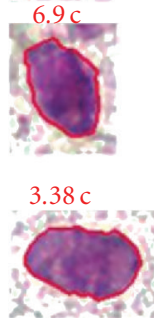

$4.7 \mathrm{c}$
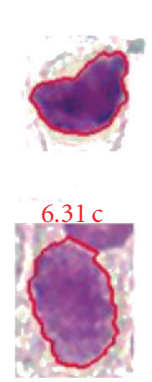

$5.15 \mathrm{c}$

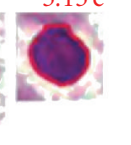

$4.69 c$
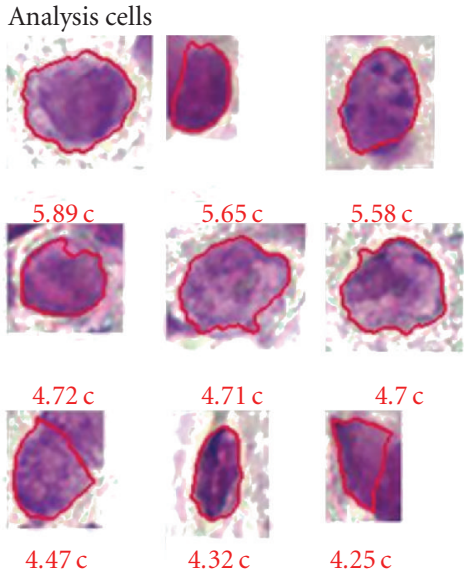

Moticyte-DNA-manual report
FIGURE 3: Six nuclei from normal and Feulgen-stained oral squamous cells with regular DNA content (green) as internal reference (around 2,0 c) and 15 from atypical cells with abnormal DNA content (red) between 4.25 c 6.90 c, indicative of malignancy.

cytological specimens (Figure 3). It aims to distinguish true prospectively malignant lesions (dysplasias) from microscopically atypical or otherwise doubtful ones. The biological basis of this ancillary method is chromosomal aneuploidy which is an accepted marker of malignant transformation of cells if it occurs clonally [24]. The cytometric DNA aneuploidy (Figure 4) utilizes the fact that gains or losses of chromosomes or their parts result in a plus or minus of more than $10 \%$ of nuclear DNA mass in a growing cell population (stemline aneuploidy) or if extremely high nuclear DNA values $>9 \mathrm{c}$ (single-cell aneuploidy) occur [24]. DNA stemlines (modal values) outside $2 \mathrm{c}, 4 \mathrm{c}$, or $8 \mathrm{c} \pm 10 \%$ are regarded as abnormal (resp., aneuploid, Figure 4) [23, 25]. Measurements may be performed on previously stained slides after destaining and Feulgen restaining. Morphologically suspicious cells are interactively selected on a monitor, and internal calibration is performed with normal (e.g., intermediate squamous) cells (Figure 3). The method has been internationally standardized and is applicable to many different epithelial dysplasias [24-26]. After enzymatic cell separation, DNA image cytometry (ICM) can also be applied on formalin-fixed and paraffin-embedded tissues, that is on all histologic routine specimens like biopsies and resected tissues [27]. Thus, even histologic diagnoses of dysplasias can be subjected to DNA cytometry to predict their prospective behavior.

Remmerbach et al. [5] reported a frequency of $13.9 \%$ doubtful or suspicious oral cytological diagnoses due to 
different grades of squamous dysplasia or abnormal regenerating epithelium. Applying DNA aneuploidy as a marker for prospective malignancy on identical slides, they could improve diagnostic sensitivity of cytology for the detection of oral cancer from $91.3 \%$ to $97.8 \%$ and specificity from $95.1 \%$ to $100 \%$. Thus $29.4 \%$ of oral cancers that clinically appeared as leukoplakias or erythroplakias were detected in stages Tis or T1. In a similar study Maraki et al. [12] described a sensitivity of $100 \%$ and specificity of $97.4 \%$ for the combined cytological and DNA cytometric evaluation of oral leukoplakias and erythroplakias. $8.1 \%$ of their cytological diagnoses had been equivocal. DNA-ICM was only applied if one of the above-mentioned diagnoses (mainly dysplasias) had occurred. Seven cases in which combined cytological/DNA cytometric diagnosis of early oral cancer was achieved up to two and half years before definitive biopsy diagnosis have been published $[12,13]$. Thus DNA-ICM may help to predict the prospective behavior of cytologically suspicious lesions, as the positive predictive value of DNA aneuploid findings was reported to be $100 \%$ and the negative value $98.1 \%[13,20]$.

Another auxiliary method that allows assessment of potential malignancy of dysplastic or regenerating cells is AgNOR analysis. AgNORs represent silver-stainable nucleolar organizer regions (Figure 5). Their number and size are related to protein synthesis. Remmerbach et al. [13, 23] showed that counting the number of silver nitrate-stained nucleolar organizer regions (AgNORs) in about 100 atypical squamous cells allows $100 \%$ sensitivity and specificity of oral cancer detection on brush biopsies.

Both methods, DNA-ICM and AgNOR analysis, may even be performed sequentially on identical cells (Figure 5). This type of multimodal cell analysis is especially useful if only few atypical cells are available [23]. Thus, AgNOR analysis can be combined with DNA-ICM if the latter does not yield an unequivocal result.

\section{Role in Therapy}

Treatment method of choice in patients with squamous cell carcinomas of the head and neck area is still surgical resection of the tumor and dissection of the regional lymph nodes. Although options for repair and restoration (e.g., free flaps) of skin and bone defects after primary surgery have improved significantly in the last decades, patients with squamous cell carcinomas of the oral cavity have only a fair prognosis with an overall 5 -year survival rate of about $45 \%$ [1]. This figure has not substantially improved during the past 30 years $[2,28,29]$. Locoregional failure after surgery or even after combined surgery and radiotherapy is the main cause of death in patients with squamous cell carcinomas of the mandibular region and the maxilla. The main principle in tumor surgery is the effort to achieve tumor-free resection margins.

Several authors have evaluated the relationship between locoregional recurrence of the tumor and the status of the resection margins $[30,31]$. The prevalence of tumoral infiltration at the resection margins varies from $3.5 \%$ to

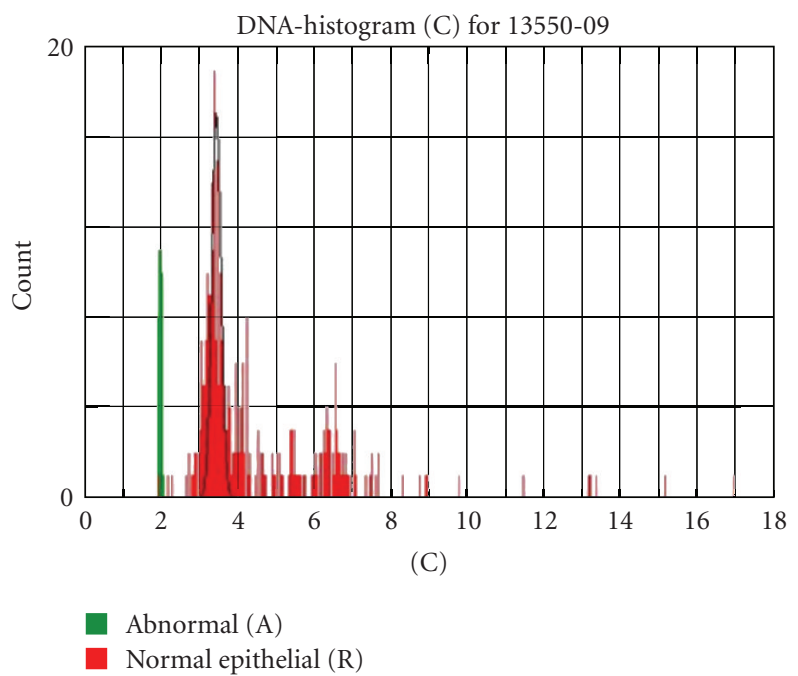

FIGURE 4: DNA histogram of in-situ oral carcinomas cells, revealing abnormal stemlines (red) at $3.5 \mathrm{c}$ and $6.5 \mathrm{c}$, and values up to $17 \mathrm{c}$ (DNA aneuploidy), indicative of malignancy. Normal epithelial cells (green bars) at $2 \mathrm{c}$.

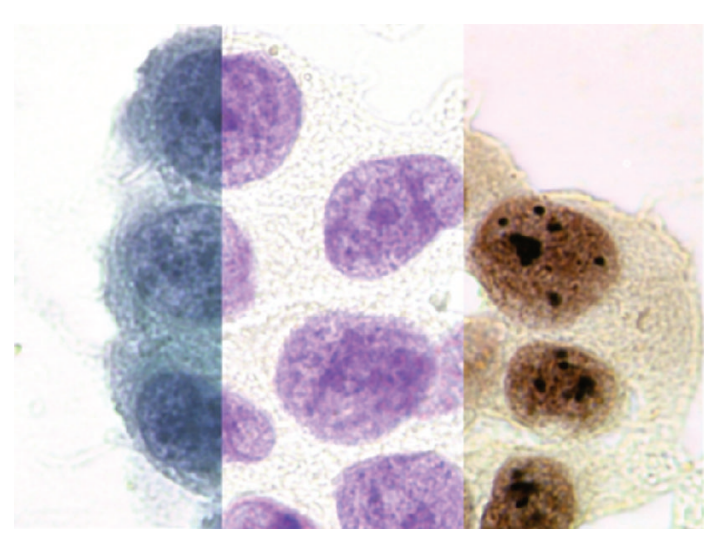

FIGURE 5: Illustration of three sequential stainings of identical oral cancer cells as performed in multimodal cell analysis [27]: Papanicolaou, Feulgen for DNA analysis, and silver nitrate for AgNOR analysis. Black dots represent AgNORs.

$60 \%[30]$ and is usually an indicator for additional excision, postoperative irradiation, and strict followup [32]. The recurrence rate in patients with positive surgical margins treated only by surgery ranges from $36 \%$ [31] to $64 \%$ [30], and when postoperative radiotherapy is used, the recurrence rate decreases to $31 \%$ [30]. Due to the fact that it can be difficult to distinguish between squamous cell carcinomas and other lesions of the oral mucosa using only haematoxylin and eosin-stained sections [33] the resection margins are routinely examined by immunohistology. Nevertheless, the histological diagnoses of oral mucosa lesions fail sometimes $[34,35]$. These days, an alternative method for the examination of oral lesions is exfoliative cytology. It is based on the technique of Papanicolaou, which is accepted worldwide, as a successful method in order to screen for epithelial dysplasias in situ or invasive carcinomas of the uteri cervix. Moreover, 
DNA image cytometry has been introduced for diagnosis of malignant transformation of squamous epithelial cells as an adjuvant tool to the cytological examination $[20,36]$. This is used to detect the cytometric equivalent of chromosomal or DNA aneuploidy [37], which is accepted as a marker for the neoplastic transformation of cells. DNA image cytometry has been introduced as an adjuvant tool for the detection of these cell transformations in oral mucosa [20, 36]. The detection of DNA aneuploidy has been described as a diagnostic aid for the identification of prospective malignancy in various organs for example in dysplasias of the uterine cervix [38], suspicious cystic lesions of the neck, [39] or bile duct brushings [40]. The positive predictive value of DNA aneuploidy for the subsequent deletion of histologically confirmed cancer was $100 \%$ in cells of these tissues. In another study, the additional value of DNA image cytometry regarding the occurrence of a locoregional relapse was assessed [27]. In this study adjuvant use of DNA image cytometry showed a high positive predictive value of $87.5 \%$ with respect to the local recurrence of head and neck squamous cell carcinomas. Recently, Brandizzi and coworkers reported a ploidy analysis in oral squamous cell carcinomas using methodologic adjustments to improve the accuracy of the measurements of aggressiveness of prognostic value. Several indices of aggressiveness were analyzed in relation to the clinical-pathologic data and evolution of the patients. Two indices had a prognostic value of the degree of aggressiveness of oral SCC [41].

Taking into account that the diagnosis of tumor infiltration in the resection margins has often serious consequences (followup resection and/or postoperative irradiation), the presence of aneuploid cells could also change the treatment. However, it is unclear if these aneuploid cells cause the locoregional tumor relapse. Unfortunately, up to date no studies exist which confirm this. Thus, it has to be investigated in a consecutive clinical trial, whether the additional or modified treatment leads to a longer relapse-free period.

In conclusion, the additional use of DNA image cytometry is a reasonable tool for the assessment of the resection margins of SCCs. DNA image cytometry could help to find the appropriate treatment option for the patients and thus might improve their prognosis.

\section{Followup Care}

Local recurrences of oral cancer after operation are frequent events, more often following R 1/2-but even after R0resections [27]. Exfoliative cytology allows the non-invasive evaluation of macroscopically suspicious mucosal lesions that may appear after resection. As brush biopsies are better tolerated by patients than scalpel biopsies, they may be performed more often. Thus, recurrences may be identified earlier.

\section{Conclusion}

DNA image cytometry has tremendous impact on early diagnosis and therapeutical considerations in head and neck squamous cell cancer. While oral lesions that macroscopically are urgently suspicious for cancer shall be submitted to scalpel biopsy and histologic evaluation, the majority of facultatively precancerous lesions, such as leuko- and erythroplakias or even persistent lichen planus lesions, may be assessed by brush biopsy and cytology. As this non-invasive procedure is well tolerated by patients, more lesions may be screened and thus more oral cancers may be found in early, curable stages. Oral brush biopsies can easily be performed by dentists, dental surgeons, and general practitioners. While sensitivity of exfoliative cytology alone is about $4 \%$ less than bioptic histology, the combination of the latter with DNA image cytometry reaches the same diagnostic accuracy as the former. As clonal chromosomal aneuploidy and DNA aneuploidy mostly precede cytological and histological evidence of malignancy in the squamous epithelium, its detection allows the diagnosis of oral squamous cell carcinomas up to two years earlier. Moreover, the additional use of DNA image cytometry is a reasonable tool for the assessment of the resection margins of squamous cell carcinomas. DNA image cytometry could help to find the appropriate treatment option for the patients and thus might improve their prognosis.

Finally, diagnostic DNA image cytometry is an accurate method and has internationally been standardized. Actually, it is paid by the German health insurances.

\section{References}

[1] H. Platz, R. Fries, and M. Hudec, "Retrospective DOSAK study on carcinomas of the oral cavity: results and consequences," Journal of Maxillofacial Surgery, vol. 13, no. 4, pp. 147-153, 1985.

[2] J. Shah and W. Lydiatt, "Buccal mucosa, alveolus, retromolar trigone, floor of the mouth, hard palate, and tongue tumors," in Comprehensive Management of Head and Neck Tumors, S. Thawley et al., Ed., pp. 686-694, WB Saunders Co, Philadelphia, Pa, USA, 1999.

[3] R. Mehrotra, M. Hullmann, R. Smeets, T. E. Reichert, and O. Driemel, "Oral cytology revisited," Journal of Oral Pathology and Medicine, vol. 38, no. 2, pp. 161-166, 2009.

[4] P. Sloan and A. Böcking, "Oral cavity," in Gray's Diagnostic Cytopathology, W. Gray and G. Kocjan, Eds., pp. 253-264, Churchill Livingstone, London, UK, 2010.

[5] T. W. Remmerbach, S. N. Mathes, H. Weidenbach, A. Hemprich, and A. Böcking, "Noninvasive brush biopsy as an innovative tool for early detection of oral carcinomas," Mund-, Kiefer- und Gesichtschirurgie, vol. 8, no. 4, pp. 229-236, 2004.

[6] S. K. Mithani, W. K. Mydlarz, F. L. Grumbine, I. M. Smith, and J. A. Califano, "Molecular genetics of premalignant oral lesions," Oral Diseases, vol. 13, no. 2, pp. 126-133, 2007.

[7] A. Trullenque-Eriksson, M. Muñoz-Corcuera, J. CampoTrapero, J. Cano-Sánchez, and A. Bascones-Martínez, "Analysis of new diagnostic methods in suspicious lesions of the oral mucosa," Medicina Oral, Patologia Oral y Cirugia Bucal, vol. 14, no. 5, pp. E210-E216, 2009.

[8] O. Kujan, A. Khattab, R. J. Oliver, S. A. Roberts, N. Thakker, and P. Sloan, "Why oral histopathology suffers inter-observer variability on grading oral epithelial dysplasia: an attempt to understand the sources of variation," Oral Oncology, vol. 43, no. 3, pp. 224-231, 2007. 
[9] J. B. Epstein, "Oral malignancies associated with HIV," Journal of the Canadian Dental Association, vol. 73, no. 10, pp. 953956, 2007.

[10] J. B. Epstein, "Mucositis in the cancer patient and immunosuppressed host," Infectious Disease Clinics of North America, vol. 21, no. 2, pp. 503-522, 2007.

[11] J. F. Bremmer, B. J. M. Braakhuis, A. Brink et al., "Comparative evaluation of genetic assays to identify oral pre-cancerous fields," Journal of Oral Pathology and Medicine, vol. 37, no. 10, pp. 599-606, 2008.

[12] D. Maraki, J. Becker, and A. Boecking, "Cytologic and DNAcytometric very early diagnosis of oral cancer," Journal of Oral Pathology and Medicine, vol. 33, no. 7, pp. 398-404, 2004.

[13] T. W. Remmerbach, H. Weidenbach, A. Hemprich, and A. Böcking, "Earliest detection of oral cancer using non-invasive brush biopsy including DNA-image-cytometry: report on four cases," Analytical Cellular Pathology, vol. 25, no. 4, pp. 159166, 2003.

[14] A. Gillenwater, V. Papadimitrakopoulou, and R. RichardsKortum, "Oral premalignancy: new methods of detection and treatment," Current Oncology Reports, vol. 8, no. 2, pp. 146154, 2006.

[15] L. Barnes, J. W. Eveson, P. Reichart, and D. Sidransky, Pathology and Genetics of Head and Neck Tumours, vol. 9 of World Health Organization Classification of Tumours, IARC Press, Lyon, France, 2005.

[16] D. Maraki, S. Yalcinkaya, N. Pomjanski, M. Megahed, A. Boecking, and J. Becker, "Cytologic and DNA-cytometric examination of oral lesions in lichen planus," Journal of Oral Pathology and Medicine, vol. 35, no. 4, pp. 227-232, 2006.

[17] M. D. Mignogna, S. Fedele, and L. Lo Russo, "Dysplasia/neoplasia surveillance in oral lichen planus patients: a description of clinical criteria adopted at a single centre and their impact on prognosis," Oral Oncology, vol. 42, no. 8, pp. 819-824, 2006.

[18] J. J. Sciubba, "Oral cancer: the importance of early diagnosis and treatment," American Journal of Clinical Dermatology, vol. 2, no. 4, pp. 239-251, 2001.

[19] J. Giunta, I. Meyer, and G. Shklar, "The accuracy of the oral biopsy in the diagnosis of cancer," Oral Surgery, Oral Medicine, Oral Pathology, vol. 28, no. 4, pp. 552-556, 1969.

[20] T. W. Remmerbach, H. Weidenbach, N. Pomjanski et al., "Cytologic and DNA-cytometric early diagnosis of oral cancer," Analytical Cellular Pathology, vol. 22, no. 4, pp. 211-221, 2001.

[21] R. Navone, P. Burlo, A. Pich et al., "The impact of liquid-based oral cytology on the diagnosis of oral squamous dysplasia and carcinoma," Cytopathology, vol. 18, no. 6, pp. 356-360, 2007.

[22] P. Klanrit, M. Sperandio, A. L. Brown et al., "DNA ploidy in proliferative verrucous leukoplakia," Oral Oncology, vol. 43, no. 3, pp. 310-316, 2007.

[23] T. W. Remmerbach, D. Meyer-Ebrecht, T. Aach et al., "Toward a multimodal cell analysis of brush biopsies for the early detection of oral cancer," Cancer Cytopathology, vol. 117, no. 3, pp. 228-235, 2009.

[24] A. Bocking, F. Giroud, and A. Reith, "Consensus report of the ESACP task force on standardization of diagnostic DNA image cytometry. European Society for Analytical Cellular Pathology," Analytical and Quantitative Cytology and Histology, vol. 8, no. 1, pp. 67-74, 1995.

[25] G. Haroske, J. P. A. Baak, H. Danielsen et al., "Fourth updated ESACP consensus report on diagnostic DNA image cytometry," Analytical Cellular Pathology, vol. 23, no. 2, pp. 89-95, 2001.
[26] A. Böcking and V. Q. Huy Nguyen, "Diagnostic and prognostic use of DNA image cytometry in cervical squamous intraepithelial lesions and invasive carcinoma," Cancer, vol. 102, no. 1, pp. 41-54, 2004.

[27] J. Handschel, D. Öz, N. Pomjanski et al., "Additional use of DNA-image cytometry improves the assessment of resection margins," Journal of Oral Pathology and Medicine, vol. 36, no. 8, pp. 472-475, 2007.

[28] J. Handschel, H. Herbst, B. Brand, U. Meyer, and J. Piffko, "Intraoral sebaceous carcinoma," British Journal of Oral and Maxillofacial Surgery, vol. 41, no. 2, pp. 84-87, 2003.

[29] N. Katase, R. Tamamura, M. Gunduz et al., "A spindle cell carcinoma presenting with osseous metaplasia in the gingiva: a case report with immunohistochemical analysis," Head and Face Medicine, vol. 4, no. 1, article 28, 2008.

[30] L. A. Ravasz, P. J. Slootweg, G. J. Hordijk, F. Smit, and I. van der Tweel, "The status of the resection margin as a prognostic factor in the treatment of head and neck carcinoma," Journal of Cranio-Maxillo-Facial Surgery, vol. 19, no. 7, pp. 314-318, 1991.

[31] R. H. Spiro, O. Guillamondegui, A. F. Paulino, and A. G. Huvos, "Pattern of invasion and margin assessment in patients with oral tongue cancer," Head and Neck, vol. 21, no. 5, pp. 408-413, 1999.

[32] J. C. de Vicente, O. R. Recio, S. L. Pends, and J. S. LópezArranz, "Oral squamous cell carcinoma of the mandibular region: a survival study," Head and Neck, vol. 23, no. 7, pp. 536-543, 2001.

[33] M. Slater and J. A. Barden, "Differentiating keratoacanthoma from squamous cell carcinoma by the use of apoptotic and cell adhesion markers," Histopathology, vol. 47, no. 2, pp. 170-178, 2005.

[34] L. M. Abbey, G. E. Kaugars, J. C. Gunsolley et al., "Intraexaminer and interexaminer reliability in the diagnosis of oral epithelial dysplasia," Oral Surgery, Oral Medicine, Oral Pathology, Oral Radiology and, vol. 80, no. 2, pp. 188-191, 1995.

[35] A. Karabulut, J. Reibel, M. H. Therkildsen, F. Praetorius, H. W. Nielsen, and E. Dabelsteen, "Observer variability in the histologic assessment of oral premalignant lesions," Journal of Oral Pathology and Medicine, vol. 24, no. 5, pp. 198-200, 1995.

[36] T. W. Remmerbach, H. Weidenbach, C. Müller et al., "Diagnostic value of nucleolar organizer regions (AgNORs) in brush biopsies of suspicious lesions of the oral cavity," Analytical Cellular Pathology, vol. 25, no. 3, pp. 139-146, 2003.

[37] A. Böcking, "DNA measurements: when and Why?" in Compendium on Quality Assurance, Proficiency Testing and Workload Limitations in Clinical Cytology, G. Wied, C. M. Keebler, D. L. Rosenthal, U. Schenck, T. M. Somrak, and G. P. Vooijs, Eds., pp. 170-188, Tutorials of Cytology, Chicago, Ill, USA, 1995,.

[38] H. J. Grote, H. V. Q. Nguyen, A. G. Leick, and A. Böcking, "Identification of progressive cervical epithelial cell abnormalities using DNA image cytometry," Cancer, vol. 102, no. 6, pp. 373-379, 2004.

[39] S. Nordemar, E. Tani, A. Högmo, M. Jangard, G. Auer, and E. Munck-Wikland, "Image cytometry DNA-analysis of fine needle aspiration cytology to aid cytomorphology in the distinction of branchial cleft cyst from cystic metastasis of squamous cell carcinoma: a prospective study," Laryngoscope, vol. 114, no. 11, pp. 1997-2000, 2004.

[40] M. C. Osterheld, S. Andrejevic Blant, L. Caron et al., "Digital image DNA cytometry: a useful tool for the evaluation of 
malignancy in biliary strictures," Cellular Oncology, vol. 27, no. 4, pp. 255-260, 2005.

[41] D. Brandizzi, H. E. Lanfranchi, and R. L. Cabrini, "Ploidy study in oral carcinomas: use of improved methodology to assess its clinical prognostic value," Oral Surgery, Oral Medicine, Oral Pathology, Oral Radiology and Endodontology, vol. 108, no. 3, pp. 406-412, 2009. 


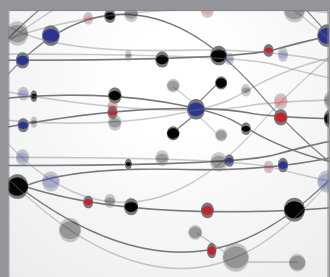

The Scientific World Journal
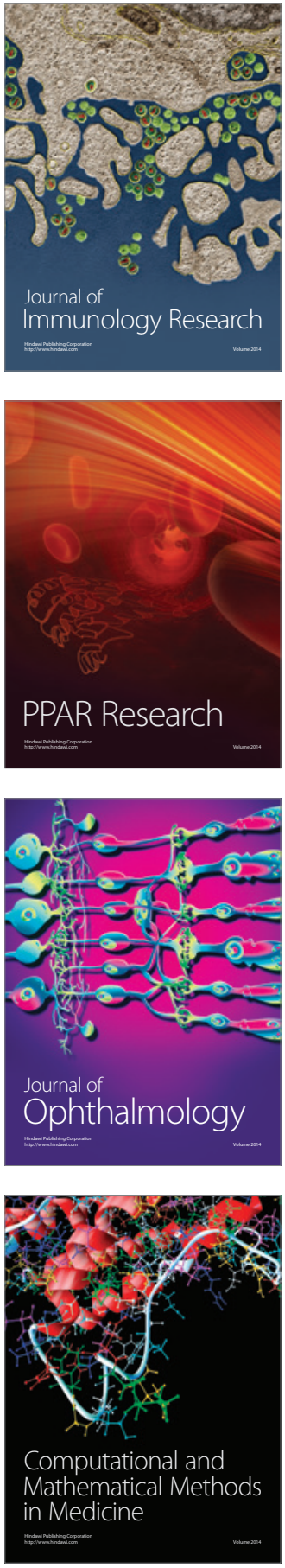

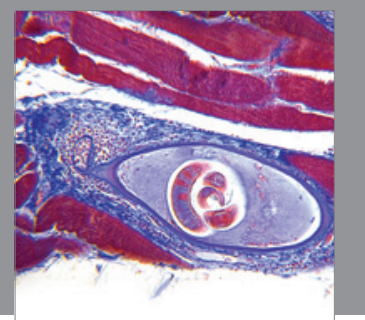

Gastroenterology

Research and Practice
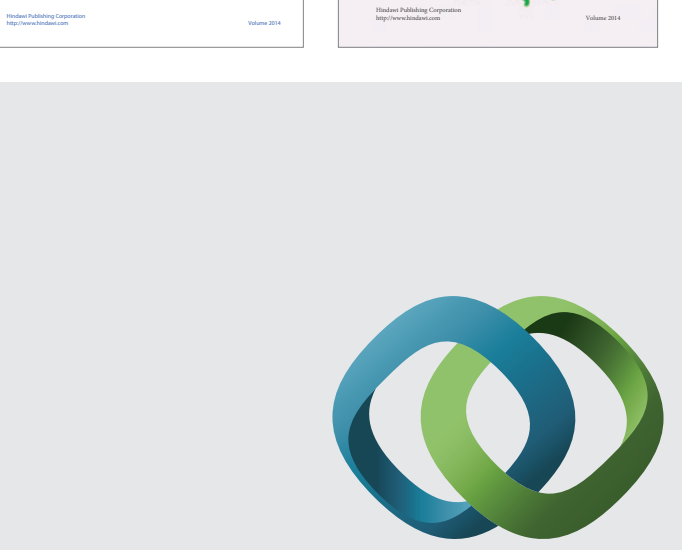

\section{Hindawi}

Submit your manuscripts at

http://www.hindawi.com
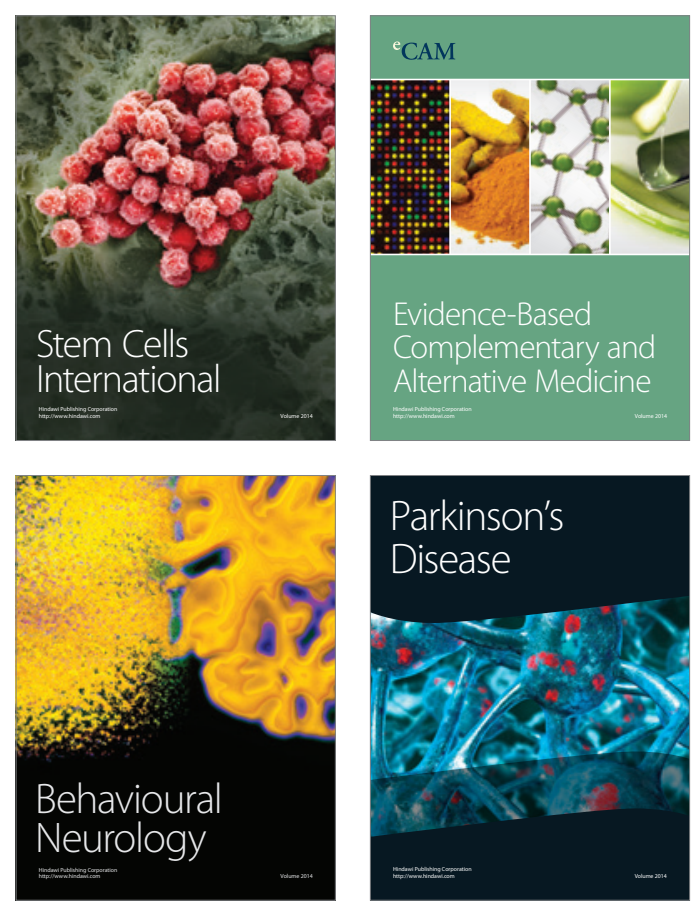

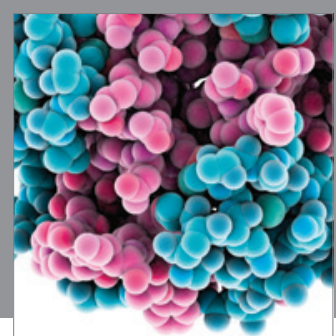

Journal of
Diabetes Research

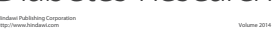

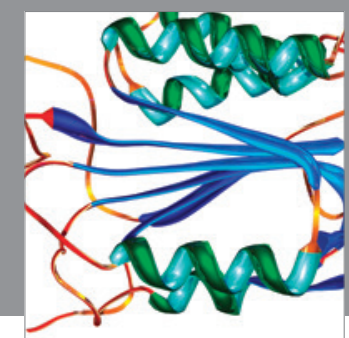

Disease Markers
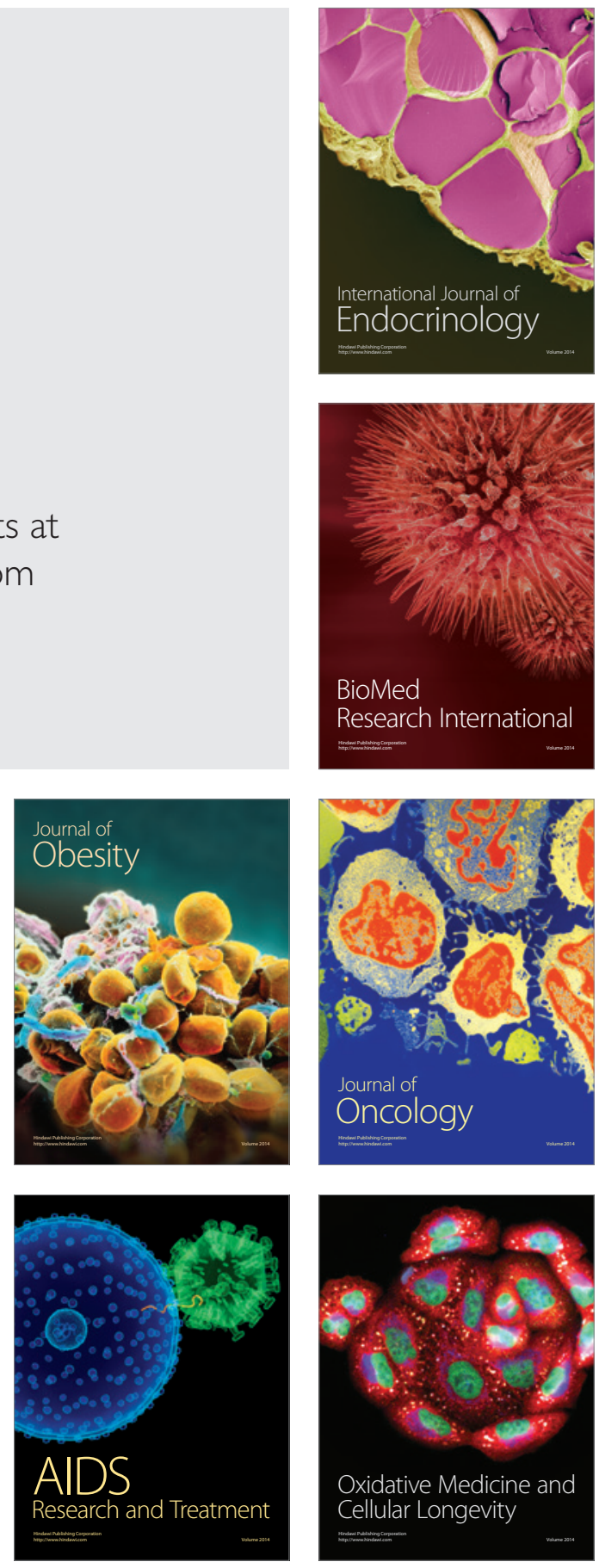